\title{
A importância da monitoria na disciplina de sistema geométrico de representação
}

\author{
The importance of monitoring in the subject \\ of geometric representation system
}

\begin{abstract}
Maria da Conceição Amaral Alves

Profa Ms. Universidade Estadual de Feira de Santana UEFS, Feira de Santana, Bahia, Brasil

amaral@uefs.br

\section{Liliane Lopes Machado}

Graduanda do Curso de Licenciatura em Matemática da Universidade Estadual de Feira de Santana - BA

liiane.lopes18@gmail.com

Kéren Cássia Alves dos Santos Monteiro

Graduanda do Curso de Licenciatura em Matemática da Universidade Estadual de Feira de Santana - BA keeuum.fsa@gmail.com
\end{abstract}

\section{RESUMO:}

A monitoria desenvolve autonomia e contribui de maneira contundente no processo de formação acadêmica e profissional. Neste artigo, relata-se a experiência de duas alunas-monitoras e respectiva atuação na disciplina de Sistema Geométrico de Representação que faz parte do primeiro semestre do curso de Licenciatura em Matemática da Universidade Estadual de Feira de Santana, sob a orientação da professora. Compreende-se que esta disciplina fornece subsídios para outras áreas que compõem a grade curricular do curso e que a monitoria é vista como um recurso pedagógico no processo de aprendizagem. 0 artigo se fundamenta na pesquisa descritiva e bibliográfica, buscando maior aproximação com a temática quanto ao seu significado, através de produções em livros, artigos e dissertações. Durante todo o período de monitoria, a qual se encontra em andamento, evidencia-se a relevância da experiência, pois além de proporcionar um crescimento pessoal e profissional, proporciona uma visão clara da realidade docente.

\section{Palavras-chave: monitoria; sistema geométrico; ensino; aprendizagem.}

\section{ABSTRACT:}

Monitoring develops autonomy and makes a decisive contribution to the process of academic and professional training. In this article, we report the experience of two student-monitors and their respective performance in the discipline of Geometrical Representation System, which is part of the first semester of the Licentiate Degree in Mathematics course at the State University of Feira de Santana, under the guidance of the professor. It is understood that this subject provides subsidies for other areas that make up the course curriculum and that monitoring is seen as a pedagogical resource in the learning process. The article is based on descriptive and bibliographic research, seeking a closer approach to the theme as to its meaning, through productions in books, articles and dissertations. During the entire monitoring period, which is in progress, the relevance of the experience is highlighted, as in addition to providing personal and professional growth, it provides a clear view of the teaching reality.

Keywords: monitoring; geometric system; teaching; learning. 


\section{INTRODUÇÃO}

0 artigo trata-se de um relato de experiência de duas alunas na condição de monitoras da disciplina Sistema Geométrico de Representação (SGR), no curso de Licenciatura em Matemática da Universidade Estadual de Feira de Santana (UEFS). Esta disciplina proporciona ao discente estabelecer uma relação com o espaço, manipulando os elementos gráficos e institui associações com as áreas de expressão gráfica e analítica, bem como propicia conhecimentos pertinentes aos fundamentos da Geometria Plana e Espacial de maneira que este possa desenvolver a habilidade de orientação espacial, efetuando mentalmente construções geométricas tridimensionais de modelo no espaço $(\mathrm{x}, \mathrm{y}, \mathrm{z})$, tomando por base um ambiente bidimensional $(\mathrm{x}, \mathrm{y})$, a partir das suas projeções utilizando o sistema cilíndrico ortogonal (ALVES, 2008).

0 artigo é fruto da parceria e troca de experiências entre professor e monitor. A monitoria se baseia na relação professor-monitor-aluno, sendo o monitor um intermediário nessa relação de troca mútua entre o professor e o aluno, ao passo que ensinar seus colegas auxilia o aprendizado e a aquisição de novas experiências e tem oportunizado o aprofundamento nessa área tão rica da Matemática: a Geometria. As monitoras fazem parte do Programa de Bolsa Monitoria1 gerenciado pela PROGRAD2, sendo uma remunerada desde 2018 e uma monitora voluntária desde 2019.

A disciplina SGR é extremamente significativa para o licenciando em Matemática e facilita a compreensão de outros conteúdos abordados em alguns componentes curriculares do curso, a exemplo da Geometria Analítica, Geometria Euclidiana, Cálculo Integral, entre outros.

Isto posto, temos por finalidade destacar a importância da monitoria na Instituição de Ensino Superior (IES), a concepção da atuação do monitor em relação a sua prática na monitoria da disciplina SGR, bem como demonstrar a importância da mesma disciplina no curso de Licenciatura em Matemática da UEFS.

Vale ressaltar que a fundamentação utilizada para referenciar o artigo, decorre no âmbito da Geometria Descritiva à qual dá sustentação à SGR, destacando a sua contribuição no desenvolvimento da habilidade de visualização espacial através da representação gráfica, tomando por base a pesquisa bibliográfica e descritiva. A pesquisa bibliográfica incide na análise de publicações em revistas, livros, artigos, dissertações e teses, relacionadas com o tema estudado e desenvolvido (RUIZ, 2011).

\footnotetext{
${ }^{1} \mathrm{O}$ Programa de Bolsa Monitoria é visto como processo de iniciação à docência, ao qual oportuniza ao discente do curso de graduação ofertado pela UEFS, contribuindo para a sua formação acadêmicoprofissional em determinada área do conhecimento (UEFS, 2020).

2 PROGRAD- A Pró-Reitoria de Ensino de Graduação é um órgão da Administração Central responsável pelas políticas relacionadas ao ensino de Graduação por meio da assistência técnica e pedagógica, quanto à supervisão, coordenação e acompanhamento das atividades relacionadas ao ensino de graduação (UEFS, 2020).
} 
A pesquisa descritiva estabelece relações entre as varáveis (GIL, 2010). Destaca-se a relação entre os sólidos e as vistas ortográficas, tornando perceptível a transposição da tridimensionalidade destes para o bidimensional e vice-versa. Ressalta-se que a coleta do material para desenvolver o artigo encontra-se disponível na biblioteca da UEFS e em endereços eletrônicos. A estruturação do presente artigo constitui uma sequência, com o intuito de responder as questões concernentes aos objetivos propostos, enfatizando o aperfeiçoamento de habilidades perceptivas e operativas (ALVES et al, 2015).

\section{A MONITORIA NAS INSTITUIÇÕES DE ENSINO SUPERIOR}

A atividade de monitoria é um recurso que auxilia o ensino de graduação por consequência das práticas estabelecidas e das experiências junto ao docente e, oportuniza o desenvolvimento das habilidades intrínsecas à docência. A monitoria possibilita ao discentemonitor aprofundar os conhecimentos na área de atuação, é um instrumento de aprendizado na formação acadêmica, bem como uma atividade formativa de ensino regulamentada pela Lei Federal n.o 5.540, de 28 de novembro de 1968. 0 Artigo 41 e seu parágrafo único determinam que,

As universidades deverão criar as funções de monitor para alunos do curso de graduação que se submeterem a provas específicas, nas quais demonstrem capacidade de desempenho em atividades técnicodidáticas de determinada disciplina [...]. As funções de monitor deverão ser remuneradas e consideradas título para posterior ingresso em carreira de magistério superior (JUSBRASIL, 2020, p.1).

A monitoria foi instituída para trabalhar com discentes com dificuldades em algumas disciplinas. Salienta-se que "a monitoria vem ganhando espaços no contexto da realidade educacional das instituições de Ensino Superior à medida que demonstram resultados úteis e atenda as dimensões política, técnica e humana da prática pedagógica" (CANDAU, 1986, p. 12).

O Artigo 84 da Lei de Diretrizes e Bases da Educação Nacional, em sua Lei no 9.394, de 20 de dezembro de 1996, destaca a seguinte consideração: "os discentes da educação superior poderão ser aproveitados em tarefas de ensino e pesquisa pelas respectivas instituições, exercendo funções de monitoria, de acordo com seu rendimento e seu plano de estudos" (JUSBRASIL, 2020, p.1). As experiências vivenciadas como discentes de graduação influenciam diretamente na formação profissional e a monitoria como um programa de espaço de formação para carreira universitária se mostra como uma construtora de experiência. Segundo Nunes

\footnotetext{
A monitoria acadêmica tem se mostrado nas Instituições de Educação Superior (IES) como um programa que deve cumprir, principalmente, duas funções: iniciar o aluno na docência de nível superior e contribuir com a melhoria do ensino de graduação. Por conseguinte, ela tem uma grande responsabilidade no processo de
} 
socialização na docência universitária, assim como na qualidade da formação profissional oferecida em todas as áreas, o que também reverterá a favor da formação do futuro docente (NUNES, 2007, p.46).

Com respaldo em lei, o programa de monitoria, previsto nos regimentos das instituições e nos projetos pedagógicos institucionais, tende a potencializar a melhoria do ensino de graduação, por meio da atuação de monitores em práticas e experiências pedagógicas, em disciplinas que permitam articulação entre teoria, prática e integração curricular.

\section{A IMPORTÂNCIA DA MONITORIA NA DISCIPLINA SGR}

A monitoria é uma atividade oferecida pela universidade, apesar disso, é o aluno que opta por participar da mesma ou não. É definida como um processo pelo qual os alunos monitores auxiliam seus colegas de curso nos processos de aprendizagem, sob orientação direta de um docente. A monitoria é um recurso de apoio pedagógico que visa suprimir dificuldades encontradas nos conteúdos abordados em sala de aula, proporcionando um espaço de discussões e debates acerca das temáticas e dá suporte aos alunos e professor em sala de aula nas atividades práticas e experimentais. 0 projeto de monitoria da disciplina SGR é justificado pela dificuldade encontrada pelos discentes no primeiro semestre em relação ao conhecimento do Desenho e da Geometria e contribui para diminuir a evasão da disciplina. 0 monitor contribuirá junto ao docente, no desenrolar dos conteúdos em sala de aula ajudando aos alunos a situar-se ao contexto dessa disciplina, além de desenvolver materiais didáticos que facilitarão na absorção do conteúdo. Os objetivos específicos do projeto da monitoria são:

Desenvolver a percepção espacial das formas geométricas através da análise e representação, considerando sua grandeza e dimensão baseada nas aulas teórico/prática; compreender o processo da tridimensionalidade do objeto representando-o no plano; dirimir dúvidas por meio de aprofundamento das temáticas propostas no conteúdo programático da disciplina; auxiliar o professor em sala de aula a dirimir as dúvidas dos alunos nas atividades práticas.

A referida disciplina é de grande relevância para o curso de Matemática, mas é acometida pela dificuldade de que a maioria dos ingressantes neste curso não estudou Geometria e Desenho no Ensino Básico. Sendo assim, a monitoria também busca meios que possam suprir a falta desse conhecimento e a dificuldade que o discente encontra no primeiro semestre. Ressalta-se que o Desenho ajuda a desenvolver o raciocínio lógico e espacial, reforça o aprendizado, instiga a criatividade, expressa ideias como meio de persuasão e como um método de comunicação nas atividades projetuais (ALVES et al, 2015).

O estudo baseado em Santos e Conceição (2011, p.3) aponta o fato de que nas aulas de matemática o enfoque maior é direcionado para a álgebra, 
por conta da preferência dos professores que a consideram mais fácil de ser trabalhada.

$$
\begin{aligned}
& \text { O ensino de matemática voltado ao cálculo e a mera classificação } \\
& \text { das formas geométricas que, até os dias atuais, fazem-se presentes } \\
& \text { na prática escolar são tão descontextualizados que os alunos não } \\
& \text { consideram estar adquirindo os conhecimentos de Geometria } \\
& \text { (SANTOS e CONCEIÇÃO, 2011, p.3). }
\end{aligned}
$$

Ainda assim, muitos professores não percebem a relevância da Geometria, pois mais importante que formalizar operações é estruturar o pensamento e relacionar teoria com a vivência do dia-a-dia, como situar-se no espaço. 0 conteúdo da Geometria está presente em todo lugar, até porque a mesma é fruto do estudo da nossa própria realidade.

Como resultado do descaso que acontece com a Geometria e sua representação no Ensino Básico, a maioria dos alunos ingressantes no referido curso sente grande dificuldade nessa área de atuação. Neste sentido, a disciplina SGR busca suprir as lacunas oriundas do Ensino Fundamental e Médio no que diz respeito aos conteúdos de Geometria, além de possibilitar o entendimento e concepção dos espaços construtivos. Fornece base para compreensão de vários conceitos relacionados ao curso de Matemática.

Na área de Geometria Analítica e Álgebra Linear, o estudo de vetores, retas e planos, cônicas e quádricas fazem uso das noções de estudo do ponto, da reta e do plano e outros conceitos vistos em SGR. Nos cálculos, esta disciplina apresenta também as noções de plano cartesiano, do espaço tridimensional e análise dos sólidos utilizando o sistema cilíndrico ortogonal ou método mongeano. Fonseca et al, afirmam que:

0 exercício de representação, pelo método mongeano, aprimora a percepção espacial do indivíduo, tornando-o mais perspicaz na interpretação da volumetria de um objeto. Este resultado é de fundamental importância para todo profissional que lida com modelos tridimensionais, seja na sua criação, intervenção ou análise (2001, p.44).

O domínio e a utilização do referido método mediante a projeção ortogonal são extremamente relevantes, já que transmite informações concernente ao objeto no que se refere à sua forma, dimensionamento, posição, assim como o seu detalhamento.

\section{RELATO DE EXPERIÊNCIA}

Como alunas de graduação do curso de licenciatura em matemática, reconhecemos que o exercício da monitoria é de suma importância para adquirir noções de docência e pôr em prática os embasamentos teóricos vistos no decorrer do curso. Acreditamos que a atuação na monitoria não é fácil, pois requer comprometimento e dedicação do monitor para estar em constante atualização do conteúdo e produzir materiais. Estar na posição perante aos colegas do próprio curso, sendo que a diferença está apenas em alguns semestres, nos causa em alguns momentos nervosismo e, o receio de errar torna-se inevitável. 
Na prática, pudemos auxiliar os discentes com relação à linguagem, transformando-a de formal para uma linguagem mais próxima deles. Além disso, a forma que buscamos para esclarecer os assuntos ministrados, aproximando-os da realidade, do concreto, se mostra bastante pertinente e proveitosa.

Desde o primeiro semestre nos identificamos muito com a disciplina e os conteúdos trabalhados na mesma. A nossa participação como monitoras durante o nosso tempo de atuação foi de muita aprendizagem e amadurecimento. Como monitoras tivemos a oportunidade de ter experiências tanto com o corpo discente como o corpo docente, atuando como intermediárias entre os dois. 0 trabalho com a monitoria vem constituindo um grande aprendizado e preparação para nossas vidas, instigando ainda mais o desejo de nos tornarmos professoras, mesmo diante de todos os desafios enfrentados pela educação.

\section{CONSIDERAÇÕES FINAIS}

A monitoria é de relevância notável, pois, se adquire ganhos desde o aspecto pessoal ao intelectual do monitor, perpassa pelas trocas de experiência e conhecimento, instiga o alunomonitor a perspectiva de trabalho docente no nível superior. 0 trabalho enquanto monitoras da disciplina SGR proporciona um novo olhar sobre a docência, os desafios que a cercam e os caminhos de ensino-aprendizagem que se constroem. Percebe-se que a monitoria potencializa a aprendizagem colaborativa e autorregulada dos estudantes universitários. Evidencia-se também a importância da disciplina SGR como fundamental para a construção de conhecimentos no curso de Matemática da UEFS, pois a mesma fundamenta bases de conhecimento para outras disciplinas.

\section{REFERÊNCIAS BIBLIOGRÁFICAS}

ALVES, M ${ }^{a}$ da Conceição Amaral. Geometria Descritiva: um comparativo entre o uso de instrumentos tradicionais de desenho e o computador. 2008. 144 p. Dissertação (Mestrado em Desenho). Programa de PósGraduação em Desenho Cultura e Interatividade. Universidade Estadual de Feira de Santana. Feira de Santana. Disponível em: < http://livros01.livrosgratis.com.br/cp125826.pdf>. Acesso em: 15 set. 2021.

ALVES, Maa da Conceição Amaral; FONTES, Chazy Lays Menezes; COSTA, Ivoneide de F. A Contribuição da Geometria Descritiva no Projeto Arquitetônico da Construção Civil. In: XI Seminário do Programa de PósGraduação em Desenho, Cultura e Interatividade. Anais eletrônicos. Feira de Santana, BA, 2015. 12 p. Disponível em: . Acesso em: 16 set. 2021.

BRASIL. Lei de Diretrizes e Bases da Educação Nacional (Lei no 9394/96). 1996. Disponível em: Acesso em: 15 set. 2021. 
CANDAU VMF. A didática em questão e a formação de educadoresexaltação à negação: a busca da relevância. In: candau, v. M. F. (org). A didática em questão. Petrópolis: vozes; 2000, p. 12-22.

CONCEIÇÃO. J.; SANTOS. R. 0 ensino da geometria. In: Anais do IX Congresso Internacional de Engenharia Gráfica nas Artes e no Desenho e XX Simpósio Nacional de Geometria Descritiva e Desenho Técnico, Rio de Janeiro, RJ, 2011. FONSECA, Ana Angélica S. e. et al. Geometria Descritiva: noções básicas. 4.ed. Salvador: Ed. da UFBA, 2001. 192 p.

GIL, Antônio Carlos. Como Elaborar Projetos de Pesquisa. 5.ed. São Paulo: Atlas, 2010. $184 \mathrm{p}$.

JUSBRASIL. Art. 41 da Lei 5540/68. Disponível em: Acesso em: 15 set. de 2021.

NUNES, João. Monitoria: uma estratégia de aprendizagem e de iniciação à docência. In: Mirza Medeiros dos Santos, Nostradamos de Medeiros Lins. (Orgs.). A monitoria como espaço de iniciação à docência: possibilidades e trajetórias. Natal: Editora da UFRN, 2007.

RUIZ, João Álvaro. Metodologia Científica: guia para eficiência nos estudos. 6. ed. São Paulo: Atlas, 2011. 182 p. 